\section{Causes of Childhood Blindness among Children Seen at the National Eye Centre, Kaduna, Nigeria}

\author{
Ngozika E Ezinne ${ }^{1,2^{\star}}$, Chinyere J Nnadi ${ }^{2}$, Khathutshelo $\mathrm{P}$ \\ Mashige $^{1}$ and Eghonghon E Onoikhua ${ }^{2}$
}

${ }^{1}$ Discipline of Optometry, University of KwaZulu-Natal, Durban, South Africa

${ }^{2}$ Department of Optometry, Madonna University, Elele, Nigeria

\begin{abstract}
Purpose: To determine the causes of childhood blindness among children seen at the National Eye Centre, Kaduna Nigeria.

Method: This was a retrospective chart review of children who attended the National Eye Centre Kaduna from January 2011 to December 2015. Data collected included their age, gender, and laterality of the condition and causes of childhood blindness.

Results: Case files of 2145 children aged $0-18$ years with a mean age of $5.53 \pm 4.39$ years were reviewed. Seven hundred and eighty nine (36.8\%) children including 334 females $(42.3 \%)$ and 455 males $(57.7 \%)($ Mean $=5.53, S D=4.389)$ were blind in one or both eyes. Out of 789 children with childhood blindness, 468 (59.3\%) had unilateral blindness and $321(40.7 \%)$ had bilateral blindness. The causes of childhood blindness were cataract $(52.6 \%)$, corneal opacity $(14.1 \%)$, trauma $(11.7 \%)$, glaucoma $(10.3 \%)$, retinal disorders $(5.7 \%)$ and refractive errors (5.6\%). Most of the childhood blindness was found among children between $5-12$ years (34.5\%) and 0 to 1 year $(17.8 \%)$. Four hundred and fifty nine $(58.2 \%)$ of the causes of the childhood blindness were preventable, $126(16 \%)$ were treatable and $204(25.8 \%)$ were unavoidable.
\end{abstract}

Conclusion: Most causes of childhood blindness found in children at National Eye Centre, Kaduna are preventable. A comprehensive

*Corresponding author: Ngozika E Ezinne, Discipline of Optometry, University of KwaZulu-Natal, Private Bag X54001, Durban, South Africa; Department of Optometry, Madonna University, Elele, Nigeria, Tel: +27 784711758; E-mail: ezinne. ngozi@gmail.com

Citation: Ezinne NE, Nnadi CJ, Mashigo KP, Onoikhua EE (2018) Causes of Childhood Blindness among Children Seen at the National Eye Centre, Kaduna, Nigeria. J Ophthalmic Clin Res 5: 39.

Received: December 22, 2017; Accepted: February 20, 2018; Published: March 06, 2018 and multidisciplinary approach comprising of eye examination at birth, children eye screening and early vaccination for infectious diseases, is warranted.

Keywords: Blindness; Causes; Childhood; Kaduna; Nigeria

\section{Introduction}

Childhood blindness refers to a group of diseases and conditions occurring in childhood or early adolescence $(<16$ years of age), which, if left untreated, result in blindness [1]. The World Health Organization (2010) [2] estimation showed that the number of blind children in the world has declined from 1.4 million in 1999 to the current number of 1.26 million. However, in Sub-Saharan Africa, the number has increased by $31 \%$ from 129890 to 419000 [3]. Childhood blindness is responsible for a high number of "blind years" such that even though the actual number of blind children is much smaller than the number of blind adults, the total "blind years" lived are comparable to those due to age related cataract [4]. Furthermore, blindness in children is related to child mortality. For these reasons, the control of blindness in children is considered a high priority in the World Health Organisation's (WHO) Vision 2020 initiative: The Right to Sight [5]. There are marked regional variations in the prevalence and causes of childhood blindness which reflect different socioeconomic development and under-5 mortality rates. The prevalence figures ranges from $0.3 / 1000$ children in high-income countries to $1.5 / 1000$ children in low-income countries [6].

In the poorest countries, corneal scarring due to vitamin A deficiency, measles, ophthalmia neonatorum and the use of traditional practices have been reported to be among the major causes of childhood blindness. However, these conditions are declining in many countries due to economic development, extensive measles immunisation programmes and better control of vitamin A supplementation [7].

Nigeria is a country with a very low socioeconomic status, and children make up almost $45 \%$ of its over 140 million population [8]. The mortality rate of children under 5 years is as high as $176 / 1000$ live births [8]. There is also inadequate and uneven distribution of eye care professionals between urban and rural areas of the country. Blindness is believed to be common in the northern part of Nigeria, although a national blindness survey has not been conducted. Most causes of blindness in children are avoidable but children become blind or remain blind due to lack of adequate facilities, poverty and ignorance [9].

In the period 1980-2000, only a few population-based studies were carried out in different countries. Furthermore, population-based surveys require large sample sizes and are generally costly to conduct; hence most prevalence data on the prevalence and causes of childhood blindness have come from surveys in schools for the blind. Examination of children enrolled in schools for the blind offers the opportunity to examine a large number of children quickly in a standard manner by a few examiners. However, it is acknowledged that 
children enrolled in schools for the blind make up only a small proportion of the total blind in the community and children with multiple disabilities are likely to be under-represented. Most underdeveloped countries such as Nigeria have no registers for the blind. Baseline data on the prevalence and causes of childhood blindness are important for planning blindness prevention strategies. This retrospective study was conducted to determine the causes of childhood blindness among children that attended the National Eye Centre Kaduna, Nigeria from January 2011 to December 2015. These findings will be useful for paediatric ophthalmic care, development of appropriate measures for interventions and management of avoidable causes of blindness in children in this region.

\section{Methods}

Ethical approval to conduct the study was obtained from the Ethics Committee of the Faculty of Health Science, Madonna University, Nigeria. Medical records of 2145 children (aged 18 years or younger) attending the National Eye Centre Kaduna, Nigeria between January 2011 and December 2015 were reviewed. The records contained information on medical history, family history and ophthalmological evaluation of the children. The National Eye Centre Kaduna is a government owned specialist hospital located in Kaduna South Local Government area in Kaduna State. It serves as a referral hospital for the state and its neighboring communities. It provides comprehensive ophthalmic services and facilities for the training of ophthalmologists, ophthalmic nurses and other eye care practitioners. It also provides primary and secondary level eye care services to patients. Kaduna is one of the 36 States and the third most populous State in Nigeria with an estimated population of 6.3 million people [8]. Free maternal and child health services are provided in all the 34 government owned health facilities and 116 local government owned primary health care centers.

Patients attending outpatient department at National Eye Centre Kaduna undergo a complete ocular and vision examination including external examination with either torch light and magnifying loop or slit lamp, fundoscopy, refraction, and binocular vision assessment. Visual Acuity (VA) is assessed using Snellen picture charts whereas the fixation pattern (central, steady, maintained) is taken into account in patients whose visual acuity cannot be measured. The study population included the children with visual acuity of 3/60 or worse. Children whose records showed visual acuity better than $3 / 60$ in one or both eyes were excluded. The age at presentation, gender, clinical diagnosis and age at onset of symptoms were determined from the medical records. The causes of the blindness were grouped as congenital if present at birth and non-congenital if absent from birth. To identify any disparity in the causes of blindness, the sample was sub-divided into developmental age categories as follows; Infants: birth to 1 year, Toddlers: 1 year to 3 years, Preschoolers: 3 years to 5 years, Grade-schoolers: 5 years to 12 years, Teenagers/adolescents: 12 years to 18 years [9]. The data obtained were imported into the Statistical Package for Social Sciences Software (SPSS) programme version 20 for analysis. The Chi-Square test was used to compare variables and a P-value of less than 0.05 was considered statistically significant.

\section{Results}

A total of 2145 case files of children aged $0-18$ years with a mean age of $5.53 \pm 4.39$ years were reviewed. The results showed that 789
(36.8\%) had presenting visual acuity of $3 / 60$ or worse in one or both eyes and visual acuity was not recorded for 330 (15.4\%) children.

Of the 789 children with childhood blindness, 334 (42.3\%) were females and 455 (57.4\%) were males. Childhood blindness was found to be highest (38.1\%) among children between 5-12 years and this was significantly associated with age $\left(\right.$ Pearson $\left.\mathrm{X}^{2}=13.13, \mathrm{P}=0.004\right)$ but not with gender (Pearson $\mathrm{X}^{2}=1.004, \mathrm{P}=0.316$ ). Age and gender distribution of childhood blindness are shown in table 1 .

\begin{tabular}{|c|c|c|c|c|}
\hline Age in years & Male (n) & Female (n) & Frequency (n) & $\begin{array}{c}\text { Percentage (\%) } \\
\text { frequency }\end{array}$ \\
\hline $0-1$ & 80 & 83 & 163 & 20.7 \\
\hline $1-3$ & 61 & 52 & 113 & 14.3 \\
\hline $3-5$ & 79 & 33 & 112 & 14.2 \\
\hline $5-12$ & 166 & 135 & 301 & 38.1 \\
\hline $12-16$ & 69 & 31 & 100 & 12.7 \\
\hline Total & 455 & 334 & 789 & 100.0 \\
\hline
\end{tabular}

Table 1: Age and gender distribution of childhood blindness.

\section{Causes of childhood blindness}

The major causes of childhood blindness were cataracts $(52.6 \%)$, retinal disorders $(14.1 \%)$ and trauma $(11.7 \%)$. Other causes of childhood blindness are shown in table 2 .

\begin{tabular}{|c|c|c|}
\hline Causes & Frequency (n) & Percent (\%) \\
\hline Cataract & 415 & 52.6 \\
\hline Glaucoma/Buphthalmos & 81 & 10.3 \\
\hline Refractive error & 44 & 5.6 \\
\hline Retinal disorders & 111 & 14.1 \\
\hline Cornea opacity & 45 & 5.7 \\
\hline Trauma & 93 & 11.7 \\
\hline Total & 789 & 100 \\
\hline
\end{tabular}

Table 2: Causes of childhood blindness.

\section{Cataract}

Out of the 789 children with childhood blindness, 415 (52.6\%) were blind due to cataract, 178 (43\%) of whom were aged 5 to 12 years, $68(16.4 \%)$ birth to 1 year and $60(14.5 \%)$ were 3 to 5 years old. Three hundred and eleven (74.9\%) children with childhood blindness due to cataract had congenital cataract and 104 (25.1\%) had traumatic cataract.

\section{Retinal disorder}

Of the 789 children with childhood blindness, 111 (14.1\%) children were blind due to retinal disorders, 39 (35.1\%) of whom were aged 5 to 12 years, $24(21.6 \%) 3$ to 5 years and $21(18.9 \%)$ were 1 to 3 years. Fifty (45\%) of the children had retinal pigmentosa.

\section{Glaucoma/Buphthalmos}

Eight one $(10.3 \%)$ cases of childhood blindness found were caused by glaucoma/buphthalmos and $48(60 \%)$ of the children were aged between birth to 1 year. 


\section{Cornea opacity or scar}

Corneal scarring was the cause of childhood blindness in 45 children $(5.7 \%), 37$ (95\%) of who were between 5 to 12 years old while $8(17.8 \%)$ were aged 1 to 3 years old. Twenty nine children $(64.4 \%)$ who had cornea scarring were due to measles and $16(35.6 \%)$ of whom were aged between 5 to 12 years.

Childhood factors constituted the major aetiology of blindness. These comprised measles (10\%), trauma (12.4\%); $2.3 \%$ of which was open globe injury, intrauterine e.g., maternal rubella (23.2\%) and harmful traditional eye medication $(3.2 \%)$. Others were congenital cataract of unknown etiology (36.3\%), glaucoma (8.2\%), retinal disorder $(3.4 \%)$ and refractive errors $(3.3 \%)$, of the 789 children with childhood blindness, 468 (59.3\%) had unilateral blindness while $321(40.7 \%)$ were bilaterally blind. The most common causes of unilateral blindness were trauma related complications $(72.4 \%)$ and non-traumatic corneal opacities $(27.8 \%)$. Cataracts $(31.4 \%)$, retinal disorders $(24.6 \%)$, glaucoma (18.1\%), non-traumatic corneal opacities $(13.9 \%)$ and refractive errors $(12.1 \%)$ were the main causes of bilateral blindness.

\section{Avoidable childhood blindness}

Four hundred and fifty nine cases of childhood blindness (58.2\%) recorded were preventable, 126 were treatable (16\%) and 204 (25.8\%) cases were unavoidable.

Previous surgical intervention had been performed in 225/789 $(28.5 \%)$ children: cataract surgery (109), glaucoma surgery (51), corneal graft (13), optical iridectomy (15), tarsotomy (19), refractive surgery (6) and enucleation (12).

The reported age of onset of visual loss was at birth in $42.5 \%$ of children aged less than 15 years and $6.3 \%$ among children older than 15 years. Age of onset of vision loss was not reported in over one quarter $(27.6 \%)$ of the children case files.

\section{Discussion}

The causes of childhood blindness vary across countries, across locations within a country and times due to differences in factors such as environmental, socioeconomic, geographic and ethnic backgrounds. It may also be affected by the child's own biological factors and their total wellbeing [10]. There is paucity of information on the causes of childhood blindness in many parts of Nigeria and it has not been studied extensively in community-based surveys. This retrospective review was conducted to determine the causes of childhood blindness in one of the largest tertiary eye centers in the northern part of Nigeria. More males than females were found to have childhood blindness in this study. This could be due to cultural stereotype predominant in the northern part of Nigeria. It could also be that males are at greater risk of blinding conditions than females or blind females have a higher mortality rate than blind males or the parents of blind males are more willing to seek eye care than the parents of blind females. Gilbert et al., [4] reported in their study that families less readily perceive a girl to be ill than a boy, and so health care is not sought. This may, in part, explain why virtually all studies in developing countries report higher prevalence of childhood blindness in males than females. Similar finding was reported by Abah et al., [11] in Kaduna however, a study in Enugu state South Eastern part of Nigeria recorded childhood blindness more in females than males.
Variations in the findings could be attributed to differences in geographical locations and cultural background.

Majority of the children that visited the eye centre were between 5 to 12 years old and age at first presentation in the hospital was mostly above 7 years of age which is late. Late age of presentation in this study could be because of lack of preschool vision screening program in Nigeria and parental unaware of the condition. Moreover, delay in care seeking by parents until end stage due to poverty and ignorance as well as the distance of the eye centre could also be another factor responsible for late presentation. It is also important to note that $\mathrm{Na}-$ tional Eye Centre, Kaduna is the only referral hospital in Kaduna with pediatric eye specialty services. Therefore, more tertiary eye care centers are highly advocated to be made affordable and accessible. Also most cases of childhood blindness were found among the school age group followed by infants and preschool. This might not represent the actual age of onset but rather the age at which the condition was detected by the child, parent or presentation in the hospital. It could also be because school age group represent more active and adventurous age group, making them more vulnerable as well as more exposed to harm.

Studies have shown that over $34 \%-69 \%$ of childhood blindness in Nigeria is caused by corneal opacity, which results mainly from interplay of vitamin A deficiency, measles and harmful traditional eye practices [12]. This study however, showed a low number of childhood blindness attributable to corneal opacity which reflects improved vitamin A supplementation and measles vaccination coverage in Kaduna, Nigeria. The major cause of childhood blindness found in this study was cataract. Many of these cases were un-operated for the reasons of associated complications and poor visual prognosis. Similar findings were also reported in Enugu [13] and Lagos state [14] however, studies in Cross rivers [15], Oyo [16] and Osun state [17] Nigeria recorded cornea scar and trauma as the major cause of childhood blindness. In comparing with studies outside Nigeria, cataract was also recorded as the major cause of childhood blindness in Burundi [18] and Botswana [19] but studies in Guyana [20], Vietnam [21], Poland [22], Turkey [23] and United Kingdom [3] reported retina disorder and optic nerve defect as the major causes of childhood blindness. Studies in India [24] recorded cornea scar as the major cause of childhood blindness. Cataract extraction as well as mechanisms to identify and refer children with cataract is highly indicated. In addition, specialist pediatric and optical services are necessary to effectively manage cataract in children in this region.

Over two third $(70 \%)$ of childhood cataract cases in this study were congenital. This could be due to high rate of rubella associated with poor maternal health during pregnancy, poverty, ignorance and late hospital presentation common in this region. It could also be due to poor visual outcome of cataract surgery in children because the treatment and postoperative care of these children requires special surgical experience and expensive equipment. In addition, there are different challenges including preoperative assessment, general anaesthesia, correction of aphakia, postoperative care and follow up for posterior capsular opacification associated with the management of cataract in children. Moreover, most of these children may be from poor socio-economic backgrounds and cannot afford the available cataract surgical services, especially intraocular lens implantation, which is the best option for aphakic correction in most children to reduce the incidence of post-operative amblyopia. Early detection 
followed by early referral and prompt free treatment programs for childhood cataract need to be implemented in Nigeria in order to achieve better outcomes after surgery. Similar findings were also recorded in south eastern Nigeria [25] and south-western Nigeria [26]. Contrary to the findings from this study, Heijthuijsen et al., [20] found retinal disorders as the major cause of blindness in children younger than 16 years in Suriname, Guyana. Variations in the findings reported could be due to rapid and marked socioeconomic changes in different countries. Moreover, studies have shown that as the economies of most countries continue to improve, the major causes of childhood blindness will also continue to change; retinal disorder will likely become a major cause of childhood blindness in developing countries while cataract will continue to overtake corneal scarring as the major avoidable cause in poor countries in Africa such as Nigeria [4]. Emphasis therefore needs to be placed on initiatives and programs for the control of blindness from retinal disorder and cataract in children. Table 3 provides an overview of childhood blindness studies in selected studies compared with findings of our study.

\begin{tabular}{|c|c|c|c|}
\hline Study & Year & Country/Location & $\begin{array}{c}\text { Major cause of childhood } \\
\text { blindness }\end{array}$ \\
\hline Present study & 2017 & Nigeria & Cataract \\
\hline Nallasamy et al. [19] & 2011 & Botswana & Refractive error \\
\hline Ruhagaze et al. [18] & 2013 & Burundi & Cornea scar \\
\hline Njuguna et al. [27] & 2009 & Eastern Africa & Cornea scar \\
\hline Asferaw et al. [7] & 2017 & Ethiopia & Cornea scar \\
\hline Rajendra et al. [28] & 2017 & Eritrea & Cataract \\
\hline Heijthuijsen et al. [20] & 2003 & Guyana & Retinal disorder \\
\hline Rahi et al. [29] & 1995 & India & Cornea scar \\
\hline Bhattacharjee et al. [24] & 2008 & India & Cornea scar \\
\hline Sitorus et al. [30] & 2007 & Indonesia & Cataract \\
\hline Muecka et al, [31] & 2009 & Myanmar & Cornea scar \\
\hline Adhikari et al. [32] & 2014 & Nepal & Cataract \\
\hline Ezegwui et al. [25] & 2003 & Nigeria & Cataract \\
\hline Fadamiro et al. [26] & 2014 & Nigeria & Cataract \\
\hline Mosuro [16] & 2012 & Nigeria & Cornea scar \\
\hline Mohammad et al. [33] & 2014 & Nigeria & Refractive error \\
\hline Akinsola et al. [14] & 2005 & Nigeria & Cataract \\
\hline Adegbehinde et al. [17] & 2007 & Nigeria & Trauma \\
\hline Duke et al. [15] & 2014 & Nigeria & Cornea scar \\
\hline Seroczyńska et al. [22] & 2001 & Poland & Optic nerve atrophy \\
\hline Cetin et al. [23] & 2004 & Turkey & Retinal disorder \\
\hline Rahi et al. [3] & 2003 & United Kingdom & Retinal disorder \\
\hline Limburg et al. [20] & 2012 & Vietnam & Refractive error \\
\hline Bamashmus et al. [34] & 2010 & Yemen & Retinal disorder \\
\hline
\end{tabular}

Table 3: Studies on the causes of childhood blindness.

Most (59.3\%) cases of childhood blindness found in the current study were unilateral and were mostly caused by trauma (cataract) and cornea (opacity) related complications. Similar finding was reported by Duke et al., [15] in Cross rivers state Nigeria. Contrary to that, a study in Osun state [17] Nigeria reported more cases of bilateral blindness than unilateral. Cataract, glaucoma and retinal disorder caused most of the bilateral blindness found in this study. This is similar to a study in Lagos [14] Nigeria but contrary to the findings from studies in Oyo state [16] Nigeria where bilateral measles keratopathy or vitamin A deficiency was recorded as the major cause of bilateral blindness. Also a study in Botswana [19] recorded refractive error as the major cause of bilateral childhood blindness. High cases of trauma recorded in the current study and some other places in Nigeria could be attributed to the violence and civil unrest witnessed in some parts of Nigeria over the years which have gravely affected lives and exposed a lot of children to harm and danger. Bilateral measles keratopathy recorded in Oyo state Nigeria indicates poor distribution of Vitamin A supplement as a result of inadequate eye care services in that region. Different approaches towards eye health education and improving access to eye care services for children are highly advised.

The current study recorded over $70 \%$ of avoidable (treatable causes + preventable causes) childhood blindness like traumatic (cataract, cornea opacity and open globe injury), cataract from rubella, refractive error, non traumatic cornea opacity from the use of traditional medications, measles and Vitamin A deficiency. This could be an indication of poor primary eye care services in this region implying that early vision screening, immunization, creation of eye care awareness programs, as well as provision of specialty ophthalmology services including medical, surgical and rehabilitative facilities could go a long way towards reducing childhood blindness in this region. Similar findings were reported in Osun [17], south-west [26] and southeast [25] Nigeria. Studies in Botswana [19], Vietnam [21], Guyana [20] and Turkey [23] were also consistent with findings from this study. However, over $70 \%$ of cases of childhood blindness found in a study in the United Kingdom [3] were unavoidable. Differences in the findings reported could be due to variations in race, socioeconomic factors and geographical locations for example in underdeveloped countries like Nigeria, systems, including health systems, are often dysfunctional on account of civil unrest or for economic or political reasons resulting in high rate of preventable or avoidable causes of childhood blindness.

\section{Conclusion}

The major causes of childhood blindness at National Eye Centre, Kaduna were cataract, retinal disorders and trauma. Preventable causes of blindness can be addressed by increasing public awareness for measles immunization, promotion of breast feeding, health and nutrition education as well as continued programs for the control of VAD through child survival programs. Availability and accessibility of first aid and antibiotic eye drops would decrease the incidence of blinding corneal ulcers due to trauma, whereas treatable causes (e.g., cataract, glaucoma, refractive errors) require more specialized, pediatric ophthalmology units, systems for early identifications and referrals. A comprehensive approach including eye examination at birth, eye screening of pre-school and school children and early vaccination for infectious diseases in children is warranted. In addition, a multidisciplinary team of health care professionals including pediatricians and pediatric ophthalmologists are needed for prevention and treatment of blindness in children.

This study has certain limitations including incomplete records, selection and information bias which narrowed the conclusion derived from the retrospective data. Visual acuity was not recorded for 330 children, thus it was not possible to ascertain whether those children had blindness hence those children were excluded from the study. In addition, some of the other studies compared here used 
different methodology such as blind school or population survey and only reported details of severe vision impairment and blindness which may not allow a direct comparison with our findings. Despite these limitations, this study provides valuable information on the causes of childhood blindness in Kaduna, Nigeria. Findings from this study could be used to develop effective blindness prevention programs as well as address causes of blindness in children in Nigeria.

\section{References}

1. Rajiv K (2008) Visual Disabilities in Children Including Childhood Blindness. Middle East Afr J Ophthalmol 15: 129-134.

2. Chandna A, Gilbert C (2010) When your eye patient is a child. Community Eye Health 23: 1-3.

3. Rahi JS, Gilbert CE, Foster A, Minassian D (1999) Measuring the burden of childhood blindness. Br J Ophthalmol 83: 387-388.

4. Gilbert C, Muhit M (2012) Eye conditions and blindness in children: Priorities for research, programs, and policy with a focus on childhood cataract. Indian J Ophthalmol 60: 451-455.

5. World Health Organization (2000) Global initiative for the elimination of avoidable blindness. World Health Organization, Geneva, Switzerland.

6. Gilbert C, Foster A (2001) Childhood blindness in the context of VISION 2020--the right to sight. Bull World Health Organ 79: 227-232.

7. Asferaw M, Woodruff G, Gilbert C (2017) Causes of severe visual impairment and blindness in students in schools for the blind in northwest Ethiopia. BMJ Glob Health 2: 000264

8. http://www.worldometers.info/world-population/nigeria-population/

9. https://www.healthychildren.org

10. United Nations Children's Fund (2001) The state of world's children 2001: Early Childhood. United Nations Children's Fund, New York, USA.

11. Abah ER, Oladigbolu KK, Ahmed AO (2013) Causes of visual impairment and blindness in Kaduna State Special Education School. Niger J Surg Res 15: $17-21$

12. Kyari F, Gudlavalleti MVS, Sivsubramaniam S, Gilbert CE, Abdull MM, et al. (2009) Prevalence of Blindness and Visual Impairment in Nigeria: The National Blindness and Visual Impairment Survey. Invest Ophthalmol Vis Sci 50: 2033-2039.

13. Ahuama OC, Nwala OR (2013) Major causes of preventable blindness among the aged in Enugu East Local Government Area, Enugu State, Nigeria. Blind \&Low Vis J 2: 49-52.

14. Akinsola FB, Aribaba OT, Onakoya AO, Adefule-Ositelu AO, Majekodunmi AA (2005) Causes of childhood blindness in a tertiary hospital in Lagos. Journal of Clinical Sciences 5: 23-26.

15. Duke RE, Lewallen S, Courtright P (2014) Estimated prevalence of monocular blindness and monocular severe visual impairment in children of Cross Rivers State, Nigeria. Niger J Ophthalmol 22: 66-68.

16. Mosuro AL, Ajaiyeoba AI, Bekibele CO, Eniola MS, Adedokun BA (2012) Survey of Low Vision among Students Attending Schools for the Blind in Nigeria: A Descriptive and Interventional Study. Middle East Afr J Ophthalmol 19: 382-391.

17. Adegbehingbe BO, Taiwo O (2007) Prevalence and Pattern of Childhood Blindness in a Resource Lmited Teaching Hospital in Nigeria. Nigerian Journal of Ophthalmology 13: 3 .
18. Ruhagaze P, Njuguna KM, Kandeke L, Courtright P (2013) Blindness and severe visual impairment in pupils at schools for the blind in Burundi. Middle East Afr J Ophthalmol 20: 61-65.

19. Nallasamy S, Anninger WV, Quinn GE, Kroener B, Zetola NM, et al. (2011) Survey of childhood blindness and visual impairment in Botswana. Br J Ophthalmol 95: 1365-1370.

20. Heijthuijsen AA, Beunders VA, Jiawan D, de Mesquita-Voigt AM, Pawiroredjo J, et al. (2013) Causes of severe visual impairment and blindness in children in the Republic of Suriname. Br J Ophthalmol 97: 812-815.

21. Limburg H, Gilbert C, Hon DN, Dung NC, Hoang TH (2012) Prevalence and causes of blindness in children in Vietnam. Ophthalmology 119: 355361.

22. Seroczyńska M, Prost ME, Medruń J, Łukasiak E, Oleksiak E (2001) The causes of childhood blindness and visual impairment in Poland. Klin Oczna 103: 117-120.

23. Cetin E, Yaman A, Berk AT (2004) Etiology of childhood blindness in Izmir, Turkey. Eur J Ophthalmol 14: 531-537.

24. Bhattacharjee H, Das K, Borah RR, Guha K, Gogate P, et al. (2008) Causes of childhood blindness in the north eastern states of India. Indian J Ophthalmol 56: 495-499.

25. Ezegwui IR, Umeh RE, Ezepue UF (2003) Causes of childhood blindness: results from schools for the blind in south eastern Nigeria. Br J Ophthalmol 87: 20-23.

26. Fadamiro CO (2014) Causes of blindness and career choice among pupils in a blind school; South Western Nigeria. Ann Afr Med 13: 16-20.

27. Njuguna M, Msukwa G, Shilio B, Tomwesigye C, Courtright P, et al. (2009) Causes of severe visual impairment and blindness in children schools for the blind in Eastern Africa: Changes in the last 14 years. Ophthalmic Epidemiol 3: 151-155.

28. Gyawali G, Bhayal BK, Adikhari R, Shrestha A, Sah RP (2017) Retrospective data on the causes of childhood visual impairment in Eritrea. BMC Ophthamol 17: 209.

29. Rahi JS, Sripathi S, Gilbert CE, Foster A (1995) Childhood blindness in India: causes in 1318 blind school students in nine states. Eye (Lond) 9: 545-550.

30. Sitorus RS, Abidin MS, Prihatono J (2007) Causes and temporal trends of childhood blindness in Indonesia: study at schools for the blind in Java. Br J Opthalmol 91: 1109-1113.

31. Muecke J, Hammerton M, Aung YY, Warrier S, Kong A, et al. (2009) A survey of visual impairment and blindness in children attending seven schools for the blind in Myanmar. Ophthalmic Epidemiol 16: 370-377.

32. Adhikari S, Shrestha MK, Adhikari K, Maharjan N, Shrestha UD (2014) Factors associated with childhood ocular morbidity and blindness in three ecological regions of Nepal: Nepal pediatric ocular disease study. BMC Ophthalmol 14: 125.

33. Muhammad N, Ali ZM (2014) Finding children with blindness and visual impairment in five local government areas of Sokoto state using the key informant method. Sud J Ophthalmo 16: 19-23.

34. Bamashmus MA, Al-Akily SA (2010) Profile of childhood blindness and low vision in Yemen: a hospital-based study. Eastern Mediterr Health J 16: $425-428$. 